\title{
Loperamide, an antidiarrheal agent, induces apoptosis and DNA damage in leukemia cells
}

\author{
$\mathrm{XIN} \mathrm{HE}^{1 *}, \mathrm{LEI} \mathrm{ZHU}^{2 *}, \mathrm{SHU} \mathrm{LI}^{1}, \mathrm{ZHIGANG} \mathrm{CHEN}^{3}$ and XIAOYING ZHAO ${ }^{1}$ \\ Departments of ${ }^{1}$ Hematology, ${ }^{2}$ Clinical Laboratory and ${ }^{3}$ Oncology, The Second Affiliated Hospital, \\ Zhejiang University School of Medicine, Hangzhou, Zhejiang 310009, P.R. China
}

Received November 29, 2015; Accepted July 27, 2017

DOI: 10.3892/ol.2017.7435

\begin{abstract}
Loperamide, an antidiarrheal agent, is frequently used to treat patients with leukemia with symptoms of diarrhea during treatment. However, the effect of loperamide on leukemia cells is unknown. The MTT assay was used to explore the cytotoxic effect of loperamide on leukemia cells. Morphological analysis and flow cytometry were performed to determine the level of apoptosis in leukemia cells following loperamide treatment. Western blotting was conducted to test the activation of the apoptotic pathway. The comet assay was used to determine the DNA damage induced by loperamide. Loperamide potently inhibited the proliferation of leukemia cell lines and primary leukemia cells from 9 patients with acute myeloid leukemia (AML) and 6 patients with acute lymphocytic leukemia (ALL) in a dose-dependent manner. Loperamide increased the expression of cleaved caspase-3 and cleaved poly (ADP-ribose) polymerase, decreased the expression of myeloid cell lekeumia-1 and induced the apoptosis of leukemia cells. In addition, treatment with $20 \mu \mathrm{M}$ loperamide increased the expression level of the protein $\mathrm{rH} 2 \mathrm{ax}$ and promoted the formation of long DNA comet tails, thus triggering DNA damage in leukemia cells. Finally, DNA damage was confirmed by the activation of the ataxia telangiectasia mutated serine/threonine kinase (ATM)-checkpoint kinase 2 (Chk2) signaling pathway. The phosphorylation level of ATM (Ser1981) and Chk2 (Thr68) was activated and upregulated following DNA damage triggered
\end{abstract}

Correspondence to: Professor Xiaoying Zhao, Department of Hematology, The Second Affiliated Hospital, Zhejiang University School of Medicine, 88 Jiefang Road, Hangzhou, Zhejiang 310009, P.R. China

E-mail: zrxz@zju.edu.cn

Dr Zhigang Chen, Department of Oncology, The Second Affiliated Hospital, Zhejiang University School of Medicine, 88 Jiefang Road, Hangzhou, Zhejiang 310009, P.R. China

E-mail: pridechen@126.com

*Contributed equally

Key words: loperamide, leukemia, apoptosis, DNA damage, mechanism by loperamide. Loperamide was demonstrated to perform an inhibitory role in the growth of leukemia cell lines and primary leukemia cells. Of note, apoptosis and DNA damage were induced following loperamide treatment in leukemia cell lines and primary leukemia cells.

\section{Introduction}

Leukemia is one of the most common malignancies in China and the United States of America (1,2). Leukemia was estimated to have effected $\sim 54,270$ individuals in 2015, according to the cancer statistics of the USA, accounting for 4 and $3 \%$ of new cancer cases in males and females, respectively (2). With the advances in new chemotherapeutic drugs and the application of hematopoietic stem cell transplantation (HSCT), the overall survival rates of patients with leukemia have markedly increased in the past several decades $(3,4)$. However, patients treated with chemotherapy and HSCT have various complications, including hematological, hepatic, renal and gastrointestinal toxicity, as well as diarrhea $(5,6)$. Diarrhea is one of the most common complications, and the incidence of acute diarrhea has been reported to be $43 \%$ in patients receiving bone marrow transplantation (7). Currently, the antidiarrheal agent loperamide is effectively and frequently used to treat these patients (8). However, the effects of loperamide on leukemia cells have not been studied. Loperamide was reported to have antitumor effects in solid tumors, including liver, breast, lung, drug-resistant ovarian, gastric, osteosarcoma, renal and canine cancer cell lines $(9,10)$. However, whether loperamide exerts cytotoxic effects on leukemia cells remains unknown.

Cell apoptosis, one of the cell death pathways, serves a vital role in antitumor effects (11). Apoptosis induced by DNA damage is an important mechanism by which a variety of antitumor drugs exhibit their effects, including mitoxantrone, etoposide and bendamustine $(12,13)$. Once DNA damage is triggered by these agents, the DNA damage response (DDR) is activated, including the damage sensor $\mathrm{rH} 2 \mathrm{ax}$ and the subsequent signal transduction pathways (14-16). These pathways, including ATM-Chk2 pathway activation, phosphorylate a panel of substrates involved in cell cycle control, transcription, DNA repair and apoptosis $(17,18)$. If the lesion is mild, DNA damage is repaired through DDR, otherwise, it will lead to mutation of genes, chromosomal rearrangement or apoptosis (19). In addition, during the process of apoptosis 
triggered by DNA damage, elimination of the anti-apoptotic protein myeloid cell leukemia (Mcl-1) is required, which performs an important role in apoptosis initiation (20). Loperamide has been reported to induce apoptosis in the aforementioned cancer cell lines $(9,10)$, but the mechanisms are unclear.

To the best of our knowledge, the present study evaluated the effect of loperamide on the growth of leukemia cells for the first time. To better represent the biological properties of leukemia, primary leukemia cells from patients and leukemia cell lines were included in the present study. It was found that loperamide potently inhibited the growth of leukemia cells in a dose-dependent manner in leukemia cell lines, as well as primary leukemia cells from patients. Additionally, cell apoptosis was dose-dependently induced by loperamide. Of note, the present study demonstrated that loperamide increased $\mathrm{rH} 2 \mathrm{ax}$, activated the ataxia telangiectasia mutated serine/threonine kinase (ATM)-checkpoint kinase 2 (Chk2) signaling pathway, and induced DNA damage in leukemia cells. Therefore, the present study provides new insights into the therapeutic potential of loperamide in leukemia and unravels a novel mechanism through which loperamide inhibits leukemia cells.

\section{Materials and methods}

Chemicals and reagents. Loperamide hydrochloride was purchased from Sigma-Aldrich (Merck KGaA, Darmstadt, Germany) and dissolved in dimethyl sulfoxide (DMSO) at a stock concentration of $40 \mathrm{mmol} / \mathrm{l}$. MTT was also purchased from Sigma-Aldrich (Merck KGaA). Ficoll-Hypaque solution and Wright-Giemsa stain solution were purchased from Solarbio Life Sciences (Beijing, China). The FITC Annexin V Apoptosis Detection kit II was purchased from BD Biosciences (San Jose, CA, USA). The CometAssay ${ }^{\circledR}$ kit (25x2 well slides) was purchased from Trevigen, Inc. (Gaithersburg, MD, USA). SYBR-Green was purchased from BioTeke Corporation (Beijing, China). Mouse anti-phospho (p)-ATM (Ser1981) antibody (cat. no. AA866; 1:1,000) was purchased from Beyotime Institute of Biotechnology (Haimen, China). Rabbit anti-caspase-3 (cat. no. 9662; 1:1,000), cleaved caspase-3 (cat. no. 9661; 1:1,000), rabbit anti-B-cell lymphoma-2 (Bcl-2; cat. no. 2872; 1:1,000), rabbit anti-Bcl-2-associated X protein (Bax; cat. no. 2774; 1:1,000), rabbit anti-AKT (cat. no. 4691; 1:1,000), rabbit anti-p-AKT (Ser473; cat. no. 9018; 1:1,000), rabbit anti-signal transducer and activator of transcription 3 (STAT3; cat. no. 12640; 1:1,000), rabbit anti-p-STAT3 (Ser727; cat. no. 94994; 1:1,000), rabbit anti-p-histone H2A.X (Ser139; cat. no. 9718; 1:1,000 for western blotting, 1:100 for Immunofluorescence) rabbit anti-ATM (cat. no. 2873; 1:1,000) and rabbit anti-p-Chk2 (Thr68; cat. no. 2197; 1:1,000) antibodies were purchased from Cell Signaling Technology, Inc. (Danvers, MA, USA). Rabbit anti-p65 (cat. no. sc-372; 1:100), rabbit anti-poly(ADP-ribose) polymerase (PARP; cat. no. sc-7150; 1:1,000), mouse anti-Mcl-1 (cat. no. sc-377487; 1:1,000) and rabbit anti-Chk2 (cat. no. sc-377487; 1:1,000) antibodies, and all of the secondary antibodies including mouse anti-rabbit IgG-horseradish peroxidase (HRP; cat. no. sc-2357; 1:5,000) and rabbit anti-mouse IgG-HRP (cat. no. sc-358914; 1:5,000) were purchased from Santa Cruz Biotechnology, Inc. (Dallas, TX, USA).
Cell lines and culture conditions. A total of 10 cell lines, including 5 acute myelocytic leukemia (AML) and 5 acute lymphocytic leukemia (ALL) cell lines, were used in the present study. The 5 AML cell lines, consisting of Thp1, U937, Kg-1, Kasumi-1 and Kg-1a, and 5 ALL lines, consisting of Nalm6, Molt4, CCRF-CEM, Jurkat and SUP-B15, were obtained from the American Type Culture Collection repository (Manassas, VA, USA). The SUP-B15 cell line was cultivated in Iscove's modified Dulbecco's medium with $10 \%$ fetal bovine serum (FBS) (Gibco; Thermo Fisher Scientific, Inc., Waltham, MA, USA), while the other cell lines were maintained in RPMI-1640 medium supplemented with 10\% FBS (Gibco; Thermo Fisher Scientific, Inc.). All of the cell lines were cultivated in a humidified incubator at $37^{\circ} \mathrm{C}$ in a $5 \% \mathrm{CO}_{2}$ atmosphere.

Primary cells from patients with acute leukemia. Bone marrow samples were obtained by bone marrow aspiration from 15 patients with acute leukemia, and the primary cells were isolated using Ficoll-Paque PREMIUM (GE Healthcare Life Sciences, Little Chalfont, UK) subsequent to obtaining written informed consent from all patients included in the present study. All of the patients with leukemia were diagnosed according to the standard diagnostic criteria of World Health Organization (21). A total of 7 male patients and 8 female patients were included in the present study. The age range of these patients was 18-76 years and the primary cell percentage as determined by flow cytometry ranged between 86 and $95 \%$. All of the patients who were admitted to the Second Affiliated Hospital (Hangzhou, China) between February 2011 and November 2013 were newly diagnosed patients without any prior treatment. The study was approved by the ethics committee of The Second Affiliated Hospital, School of Medicine, Zhejiang University (Zhejiang, China) and followed the Declaration of Helsinki principles. The clinical characteristics of the 15 patients, including 9 AML and 6 ALL patients, are listed in Table I.

Cell viability assay. Cell viability was measured by MTT assay. Briefly, 5 AML (Thp1, U937, Kg-1, Kasumi-1 and Kg-1a) and 5 ALL (Nalm6, Molt4, CCRF-CEM, Jurkat and SUP-B15) cell lines and primary cells from the aforementioned 9 AML and 6 ALL patients were seeded onto 96-well plates at $\sim 70 \%$ confluence and a total volume of $200 \mu \mathrm{l}$. Following exposure to $0,2.5,5,10,20$ and $40 \mu \mathrm{M}$ loperamide for 24,48 or $72 \mathrm{~h}$, the cells were incubated with MTT (20 $\mu \mathrm{l}$, $5 \mathrm{mg} / \mathrm{ml})$ solution at $37^{\circ} \mathrm{C}$ for $4 \mathrm{~h}$. Supernatant $(100 \mu \mathrm{l})$ was then pipetted gently and $100 \mu 1$ of the joint fluid (10\% SDS, $5 \%$ isobutanol and $1 \%$ hydrochloric acid) was added to each well to dissolve the formazan crystals. The absorbance value of each well was determined at a test wavelength of $570 \mathrm{~nm}$ and the half-maximal inhibitory concentration $\left(\mathrm{IC}_{50}\right)$ of drugs was calculated.

Morphological observation. Molt4 and Thp1 cells were cultivated on 6-well plates at $37^{\circ} \mathrm{C}$ overnight and treated with $0 \mu \mathrm{M}$ (DMSO-treated) or $20 \mu \mathrm{M}$ loperamide at $37^{\circ} \mathrm{C}$ for $24 \mathrm{~h}$. The cells were then collected and transferred to glass slides. The morphological changes were observed under light microscopy (magnification, $\mathrm{x} 400$ ) and images were captured using a camera. 
Table I. Clinical characteristics of patients with leukemia.

\begin{tabular}{|c|c|c|c|c|c|c|c|}
\hline Patients & Subtype & Age & Sex & WBC (x109/1) & $\begin{array}{l}\text { Primary cell } \\
\text { percentage, } \%\end{array}$ & $\begin{array}{l}\text { Gene } \\
\text { mutation }\end{array}$ & Chromosome karyotype \\
\hline AML1 & M2 & 18 & Male & 66.8 & 94 & AML/ETO & $\begin{array}{l}46, X Y, \operatorname{der}(3) \mathrm{t}(3 ; 8)(\mathrm{p} 26 ; \mathrm{q} 13) \\
\mathrm{t}(8 ; 21)\end{array}$ \\
\hline AML2 & M2 & 30 & Female & 39.5 & 87 & $\mathrm{NO}$ & 47,XY,+mar[16]/46,XX[4] \\
\hline AML3 & M5 & 51 & Female & 7.0 & 90 & NO & $\begin{array}{l}46, X X, t(8 ; 19)(q 13 ; p 13.1) \\
\operatorname{del}(9) \\
(q 22 q 34 ; \operatorname{del}(11)(q 23)[5]\end{array}$ \\
\hline AML4 & M1 & 56 & Female & 6.0 & 95 & CEBPA & $\begin{array}{l}47, X, \mathrm{i}(\mathrm{X})(\mathrm{q} 10),+10[5] / 46, X \\
-X,+10[4]\end{array}$ \\
\hline AML5 & M4 & 45 & Male & 2.5 & 88 & FLT3-ITD & $\begin{array}{l}46, X,-Y,+8, t(8 ; 21)(q 22 ; q 22) \\
{[18] / 46, X Y[2]}\end{array}$ \\
\hline AML6 & M5 & 60 & Male & 244.7 & 93 & FLT3-ITD, dupMLL & $46, X Y[8]$ \\
\hline AML7 & M4 & 46 & Male & 35.5 & 92 & CEBPA/MYH11 & 46,XY,inv(16)(p13,1q22)[20] \\
\hline AML8 & CML-BC/M & 32 & Female & 23.9 & 90 & $\begin{array}{l}\text { BCR/ABL(P210), } \\
\text { AML1/MDS1, EVI1 }\end{array}$ & $\begin{array}{l}46, X X, t(9,22)(q 34 ; q 11.2) \\
{[18] / 46, \text { idem }, t(3 ; 21)} \\
(q 26 ; q 22)[2]\end{array}$ \\
\hline AML9 & M5 & 29 & Male & 58.0 & 95 & EVI1 & 46,XY,t(11,19)(q23,p13.1) \\
\hline ALL1 & B-ALL & 39 & Female & 4.5 & 94 & $\mathrm{NO}$ & $46, \mathrm{XX}[2]$ \\
\hline ALL2 & B-ALL & 76 & Female & 229.0 & 89 & $\mathrm{BCR} / \mathrm{ABL}(\mathrm{P} 210)$ & $46, X X, t(9,22)(\mathrm{q} 34 ; \mathrm{q} 11.2)[14]$ \\
\hline ALL3 & B-ALL & 68 & Female & 127.3 & 86 & BCR/ABL(P190) & $\begin{array}{l}46, \mathrm{XX}, \mathrm{t}(9,22)(\mathrm{q} 34 ; \mathrm{q} 11.2) \\
{[13] / 49, \mathrm{idem},+1,+5,+6[2] / 46,} \\
\text { XX[2] }\end{array}$ \\
\hline ALL4 & T-ALL & 18 & Male & 107.8 & 93 & SIL/TAL1 & $46, X Y[8]$ \\
\hline ALL5 & B-ALL & 53 & Male & 1.5 & 88 & NA & NA \\
\hline ALL6 & B-ALL & 21 & Female & 2.8 & 93 & $\mathrm{NO}$ & $46, \mathrm{XX}[2]$ \\
\hline
\end{tabular}

AML, acute myeloid leukemia; ALL, acute lymphocytic leukemia; FLT3-ITF, Internal tandem duplication of the fms-like tyrosine kinase-3 gene; CEBPA, CCAAT/enhancer binding protein $\alpha$; MYH11, myosin heavy chain 11; BCR/ABL, breakpoint cluster region/abelson; AML1/MDS1, acute myeloid leukemia 1 protein/mission demonstration satellite 1; EVI1, ecotropic virus integration site 1 protein homolog; SIL/TAL1, stem cell leukemia/T-cell acute lymphoblastic leukemia 1 interrupting locus; WBC, white blood count.

Flow cytometric cell apoptosis analysis. The assay was performed according to the manufacturer's protocol (BD Biosciences, San Jose, CA, USA). Briefly, A total of $1 \times 10^{6}$ Molt4, Thp1, ALL-P1 and AML-P1 cells were seeded on 6-well plates and treated with 0 (DMSO-treated), 5, 10 or $20 \mu \mathrm{M}$ loperamide. The cells were collected after incubation for $24 \mathrm{~h}$ and washed with PBS twice. For apoptosis analysis, the cells were re-suspended in $1 \mathrm{X}$ Binding Buffer (BD Biosciences) at a concentration of $1 \times 10^{6}$ cells $/ \mathrm{ml}$. Then, $100 \mu \mathrm{l}$ cell resuspension solution was incubated with $5 \mu \mathrm{l}$ of fluorescein isothiocyanate (FITC) Annexin V and $5 \mu \mathrm{l}$ of 7-aminoactinomycin $\mathrm{D}^{+}\left(7 \mathrm{AAD}^{+}\right)$at room temperature for $15 \mathrm{~min}$ in the dark. Another $400 \mu \mathrm{l}$ of $1 \mathrm{X}$ Binding Buffer was added and the cells were analyzed by flow cytometry within $1 \mathrm{~h}$.

Western blot analysis. Cells treated with loperamide were collected and the total proteins were extracted by radioimmunoprecipitation assay buffer (Sigma-Aldrich; Merck KGaA) containing protease and phosphatase inhibitors (Sigma-Aldrich; Merck KGaA). The proteins were determined colorimetrically, and then $30 \mu \mathrm{g} /$ lane protein was loaded and separated by $10 \%$ SDS-PAGE. The separated proteins were then blotted to polyvinylidene fluoride membranes (BD Biosciences, San Jose, CA, USA). The membrane was incubated in TBS containing 5\% skimmed milk powder at room temperature for $1 \mathrm{~h}$ and then probed with primary antibodies specific to anti-caspase-3 (cat. no. 9662; 1:1,000), cleaved caspase 3 (cat. no. 9661; 1:1,000), PARP (cat. no. sc-7150; 1:1,000), Bcl-2 (cat. no. 2872; 1:1,000), Bax (cat. no. 2774; 1:1,000), Mcl-1 (cat. no. sc-377487; 1:1,000), Akt (cat. no. 4691; 1:1,000), p-Akt (Ser473; cat. no. 9018; 1:1,000), ATM (cat. no. 2873; 1:1,000), p-ATM (cat. no. AA866; Ser1981; 1:1,000), Chk2 (cat. no. sc-377487; 1:1,000), p-Chk2 (Thr68; cat. no. 2197; 1:1,000), p-histone H2A.X (Ser139; cat. no. 9718; 1:1,000), STAT3 (cat. no. 12640; 1:1,000) or p-STAT3 (Ser727; cat. no. $94994 ; 1: 1,000)$ at $4{ }^{\circ} \mathrm{C}$ overnight. Then, the membrane was washed with TBST 3 times and incubated with the secondary antibodies, horseradish peroxidase-conjugated rabbit anti-mouse (cat. no. sc-358914; 1:5,000) and mouse anti-rabbit (cat. no. sc-2357; 1:5,000), at room temperature for $2 \mathrm{~h}$. The membrane was washed again with TBST 3 times. Then, the protein bands were visualized using an enhanced 
chemiluminescence western blotting detection system (BD Biosciences, San Jose, CA, USA) and analyzed using Quantity One ${ }^{\circledR}$ software (version 4.62; Bio-Rad Laboratories, Inc., Hercules, CA, USA).

Immunofluorescence staining. Cells treated with loperamide were transferred to the slides at $80-90 \%$ confluence by a slide centrifuge at $500 \mathrm{x} \mathrm{g}$ for 5 mins at room temperature. The cells were then fixed with freshly prepared $4 \%$ paraformaldehyde in PBS at $37^{\circ} \mathrm{C}$ for $15 \mathrm{~min}$ and permeabilized with $0.2 \%$ Triton X-100 in PBS for 15 min at room temperature. Subsequent to being blocked with PBS containing $3 \%$ bovine serum albumin (Sigma-Aldrich; Merck KGaA) for $30 \mathrm{~min}$ at room temperature, the samples were incubated with primary rabbit anti-phospho-histone H2A.X (Ser139) antibody (cat. no. 9718; 1:100) or rabbit anti-p65 antibody (cat. no. sc-372; $1: 100$ ) at $4^{\circ} \mathrm{C}$ overnight followed by the anti-rabbit-FITC secondary antibody (cat. no. sc-2359; 1:200) for $1 \mathrm{~h}$ at room temperature in the dark. The cells were mounted in mounting medium (Sigma-Aldrich; Merck KGaA) with DAPI for $15 \mathrm{~min}$ at room temperature in the dark and sealed. Immunofluorescence was observed and recorded immediately on a Zeiss Confocal Laser Scanning Microscope (magnification, x400; Carl Zeiss AG, Oberkochen, Germany).

Comet assay. To detect smaller amounts of damage, including single and double-stranded breaks, the alkaline comet assay was used. The assay was performed following instructions from Trevigen, Inc. Briefly, cells treated with loperamide were harvested and combined at $1 \times 10^{5} / \mathrm{ml}$ with molten LMAgarose (at $37^{\circ} \mathrm{C}$ ) at a ratio of 1:10 (v/v), and then transferred to comet slides. The slides were immersed in $4^{\circ} \mathrm{C}$ Lysis Solution (Trevigen, Inc. Gaithersburg, MD, USA) for $1 \mathrm{~h}$ and later in freshly prepared alkaline unwinding solution $(\mathrm{pH}>13.0)$ for $20 \mathrm{~min}$ at room temperature. The slides were then placed in an electrophoresis slide tray with the alkaline electrophoresis solution (200 mM NaOH, $1 \mathrm{mM}$ EDTA) and electrophoresis was performed under the conditions of power up to $21 \mathrm{~V}$ for $30 \mathrm{~min}$. The cells in the circle of dried agarose were stained with diluted SYBR-Green (BioTeke Corporation, Beijing, China; cat. no. 9718; EP1601-1) for $30 \mathrm{~min}$ at room temperature and then viewed on a Zeiss Confocal Laser Scanning Microscope (Carl Zeiss AG; magnification, $\mathrm{x} 400$ ). The percentage of DNA in the tail and tail length are two common descriptors of DNA damage for the alkaline comet assay, which were analyzed by the Comet Assay Software Project (CaspLab-Comet Assay Software, CASPLab 1.0.1, http://casplab.com/) (22). At least 50 randomly selected cells were analyzed per sample.

Statistical analysis. Data were confirmed through three independent experiments. The results are expressed as the mean \pm standard deviation. The differences between groups were assessed by unpaired t-test, or one-way ANOVA with a Least Significant Difference test, depending on the number of groups compared. The statistical analysis was performed by SPSS 16.0 software (SPSS, Inc., Chicago, IL, USA). $\mathrm{P}<0.05$ was considered to indicate a statistically significant difference.

\section{Results}

Loperamide inhibits growth of leukemia cell lines. To evaluate the effect of loperamide on leukemia cells, the MTT assay was performed in 5 AML cell lines and 5 ALL cell lines with different concentrations of loperamide. Loperamide significantly inhibited the growth of leukemia cell lines in a dose-dependent manner between 2.5 and $40 \mu \mathrm{M}$ (Fig. 1). Loperamide $(40 \mu \mathrm{M})$ inhibited growth of almost all the leukemia cells, to a cell viability of $<1 \%$. The $\mathrm{IC}_{50}$ values of the AML cell lines at $24 \mathrm{~h}$ were calculated, ranging between 14.83 and $17.68 \mu \mathrm{M}$, while for ALL cell lines, the $\mathrm{IC}_{50}$ values ranged between 10.66 and $14.60 \mu \mathrm{M}$ (Fig. 1). It was then determined whether loperamide inhibits the growth of these leukemia cell lines in a time-dependent manner. No significant difference in cytotoxic effect was apparent following treatment for 24, 48 or $72 \mathrm{~h}$ in AML and ALL cell lines, which indicated that loperamide exerted its inhibitory effect on leukemia cell lines to the maximal extent at $24 \mathrm{~h}$ (data not shown).

Loperamide inhibits the growth of primary cells from patients with acute leukemia. Primary cells more accurately reflect the biological properties of tumors from patients. Primary leukemia cells were isolated from patients with ALL and AML. The subtypes of patients with AML were: 1 with M1; 2 with M2; 2 with M4; 3 with M5; and 1 with chronic myelogenous leukemia-blast crisis/myeloid (M), while there were four B-ALL and one T-ALL patients. Gene mutations and chromosome karyotype abnormalities were present in 10 patients. The detailed clinical characteristics of the patients are described in Table I. The inhibitory effect of loperamide on primary cells was then assessed and it was found that loperamide could reduce the survival of the primary cells from AML and ALL primary cells, even for those with complex chromosomal abnormalities and adverse genetic mutations, in a dose-dependent manner (Fig. 2). The $\mathrm{IC}_{50}$ values of AML primary cells at $24 \mathrm{~h}$ were $11.87-25.96 \mu \mathrm{M}$, while for ALL primary cells, the $\mathrm{IC}_{50}$ values were $12.78-20.58 \mu \mathrm{M}$ (Fig. 2). Furthermore, no significant difference was observed for the inhibitory ratio of loperamide on primary cells in the time studied (data not shown).

Loperamide induces apoptosis in leukemia cell lines and primary cells. To investigate the potential mechanism of the inhibitory effects of loperamide on leukemia cells, the morphological changes in cells treated with $20 \mu \mathrm{M}$ loperamide were observed. As shown in Fig. 3, nuclear shrinkage and membrane vacuolization were observed in Molt-4 and Thp1 cells following $20 \mu \mathrm{M}$ loperamide treatment, which are features of cell apoptosis. These results indicated that the inhibitory effects of loperamide on leukemia cells may be exerted via cell apoptosis.

To confirm that the antitumor role of loperamide is mediated by cell apoptosis, cells treated with loperamide were stained with Annexin $\mathrm{V}$ and $7 \mathrm{AAD}^{+}$and analyzed by flow cytometry. The results showed a dose-dependent increase in cell apoptosis for cells treated with various concentrations of loperamide. In the absence of loperamide treatment, cell apoptosis was $<10 \%$. At a concentration of $20 \mu \mathrm{M}$, the apoptotic cell percentage in Thp1 was $62.3 \pm 5.7 \%$, while it was $78.6 \pm 3.7 \%$ in Molt 4 cells 
A

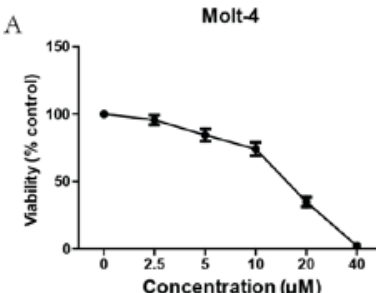

C

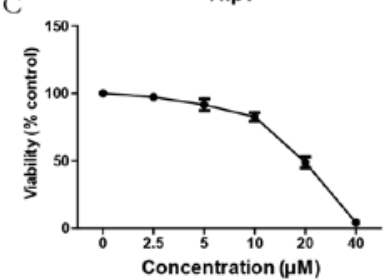

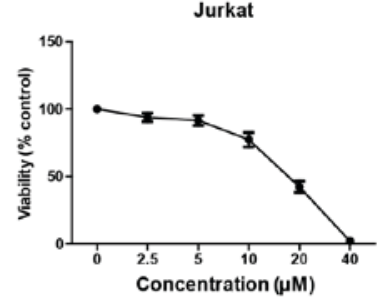

D

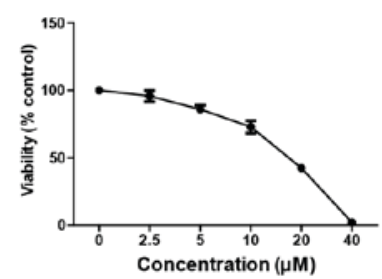

B

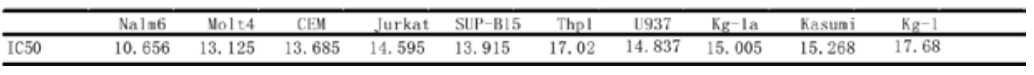

Figure 1. Loperamide inhibits the growth of leukemia cell lines in a concentration-dependent manner. (A) Molt-4, (B) Jurkat, (C) Thp1 and (D) U937 cell lines were incubated with different concentrations of loperamide for $24 \mathrm{~h}$ and the cell viability was determined by MTT assay. (E) IC $\mathrm{M}_{50}$ values of various leukemia cell lines treated with loperamide for $24 \mathrm{~h}$. $\mathrm{IC}_{50}$, half-maximal inhibitory concentration.

A

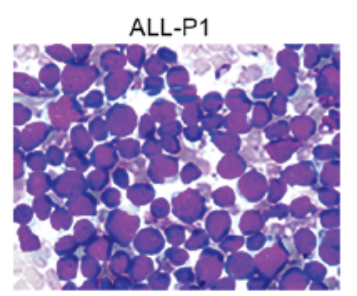

B

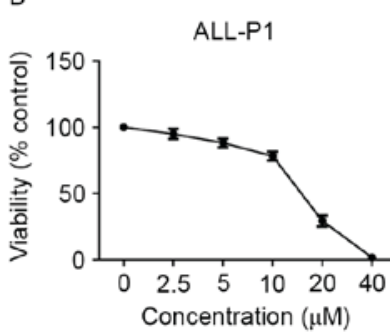

AML-P1

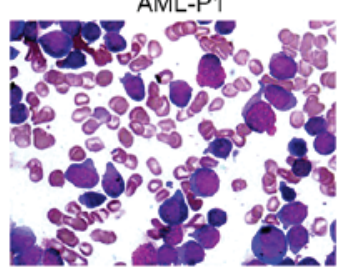

AML-P1

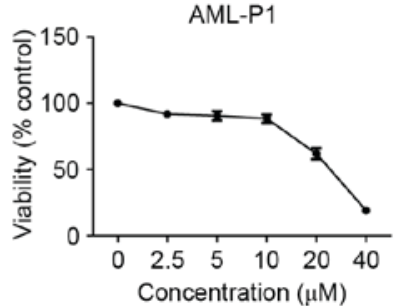

C

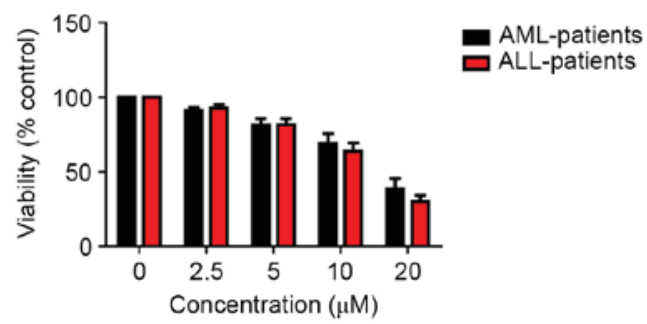

D

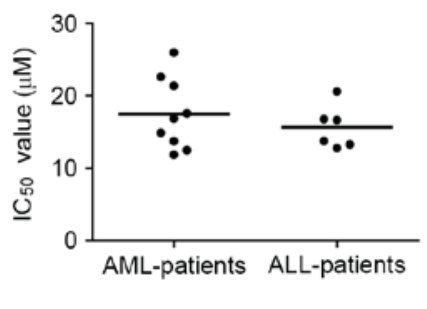

Figure 2. Loperamide inhibits the growth of primary leukemia cells from patients in a concentration-dependent manner. (A) A representative image of Wright-Giemsa stain of primary leukemia cells from ALL-P1 and AML-P1 (magnification, x400). (B) Cell viability of primary cells from ALL-P1 and AML-P1 treated with various concentrations of loperamide for $24 \mathrm{~h}$ was measured by the MTT assay. (C) Cell viability of primary cells from ALL and AML patients treated with various concentrations of loperamide for $24 \mathrm{~h}$ was measured by the MTT assay. (D) IC 50 values of primary cells from ALL and AML patients treated with loperamide for $24 \mathrm{~h}$. ALL, acute lymphocytic leukemia; AML, acute myeloid leukemia; ALL-P1, acute lymphocytic leukemia-patient 1; AML-P1, acute myeloid leukemia-patient $1 ; \mathrm{IC}_{50}$, half-maximal inhibitory concentration.

(Fig. 4A and B). The apoptotic percentage was $73.9 \pm 4.7 \%$ for ALL-P1 cells and 45.8 $\pm 4.15 \%$ for AML-P1 cells (Fig. 4A and $\mathrm{B})$. To determine the mechanisms of apoptosis induced by loperamide, western blot analysis was performed to assess caspase-3 activity and PARP, Bcl-2, Bax and Mcl-1, which are important in inducing apoptosis $(23,24)$. As shown in Fig. 4C and $\mathrm{D}$, the expression of cleaved-caspase- 3 and cleaved-PARP increased in a dose-dependent manner with loperamide treatment. To identify the upstream mechanism of apoptosis induced by loperamide in leukemia cells, the activation of the nuclear factor (NF)- $\mathrm{B}, \mathrm{c}-\mathrm{Jun} \mathrm{N}$-terminal kinase (JAK)-STAT3 and phosphoinositide 3-kinase (PI3K)/Akt pathways was measured, which perform important roles in apoptosis (25-27). Western blot analysis was performed to detect the expression of STAT3, p-STAT3, Akt and p-Akt, and immunofluorescence staining was performed to test the cellular localization of p65. The expression of STAT3, p-STAT3, Akt and p-Akt and the cellular localization of p65 was not changed following loperamide treatment (data not shown). These data indicated that loperamide did not trigger the activation of the $\mathrm{NF}-\kappa \mathrm{B}$, JAK-STAT or PI3K/Akt pathways. Although the expression of Bcl-2 and Bax was not significantly changed, Mcl-1, an 
important anti-apoptosis protein (28), was downregulated following loperamide treatment. These results indicated that loperamide inhibited the proliferation of leukemia cells and induced cell apoptosis.

Loperamide induces DNA damage and activation of the ATM-Chk2 pathway in leukemia cells. Considering the specific changes in Mcl-1 and cleaved PARP expression and the significant role of Mcl-1 and cleaved PARP in DNA damage repair, it was examined whether loperamide induced DNA damage $(29,30)$. The comet assay detects DNA damage in vitro (31). It was revealed that the length of the tail and the percentage of cells with a long tail increased as the concentration increased, which demonstrated the DNA damage-inducing effect of loperamide in a concentration-dependent manner (Fig. 5A). As demonstrated by histogram statistics, at a concentration of $20 \mu \mathrm{M}$, the percentage DNA in the tail (measured as the percentage of total DNA in the tail) reached $64.3 \pm 8.1 \%$, while the tail length was $99 \pm 3.6 \mu \mathrm{m}$ (Fig. 5B) The phosphorylation level of H2Ax, a sensitive DNA damage response marker, was then determined by western blotting and immunofluorescence staining, and the rH2Ax levels were found to be markedly elevated following treatment with $20 \mu \mathrm{M}$ loperamide for $24 \mathrm{~h}$ (Fig. 5C). The results of immunofluorescence staining showed that the intensity of $\mathrm{rH} 2 \mathrm{Ax}$ was enhanced significantly (Fig. 5D). These results suggested that loperamide increased the expression of phosphorylated $\mathrm{H} 2 \mathrm{Ax}$ and the length of the tail, causing DNA damage in leukemia.

The ATM-Chk2 pathway performs an important role in the DNA damage response (32). It was investigated whether loperamide induced DNA damage by activating the ATM-Chk2 pathway in leukemia cells. The results showed that the phosphorylation level of ATM (Ser1981) in the Molt-4 and Thp1 cell lines and primary cells treated with 5-20 $\mu \mathrm{M}$ loperamide increased compared with cells treated with DMSO (Fig. 6). Chk2, the downstream effector of ATM (32), was also examined by western blotting. The phosphorylation level of Chk2 (Thr68) was also increased in a dose-dependent manner (Fig. 6). These data indicated that loperamide induced DNA damage and activated the ATM-Chk2 pathway in leukemia cells.

\section{Discussion}

Loperamide, first synthesized in 1973, is widely prescribed and used as an antidiarrheal agent around the world (33). Blocking the $\mu$-opioid receptor of the gastrointestinal tract and antagonizing calmodulin are the two main molecular mechanisms for the antidiarrheal effect of loperamide (34-37). In previous years, loperamide was also found to possess anti-neoplastic activity in a variety of tumors in vitro, including liver, breast, lung and canine cancers $(9,10)$. However, the specific mechanism of its antitumor effect remains unclear. To the best of our knowledge, the present study investigated the effects of loperamide treatment on the growth of leukemia cells for the first time, and demonstrated that loperamide effectively inhibited the growth of leukemia cell lines and primary cells from patients with leukemia in a dose-dependent manner by inducing cell apoptosis. DNA damage triggered by loperamide treatment was involved in the molecular mechanism of its anti-leukemia effects. Furthermore, the ATM-Chk2 signaling

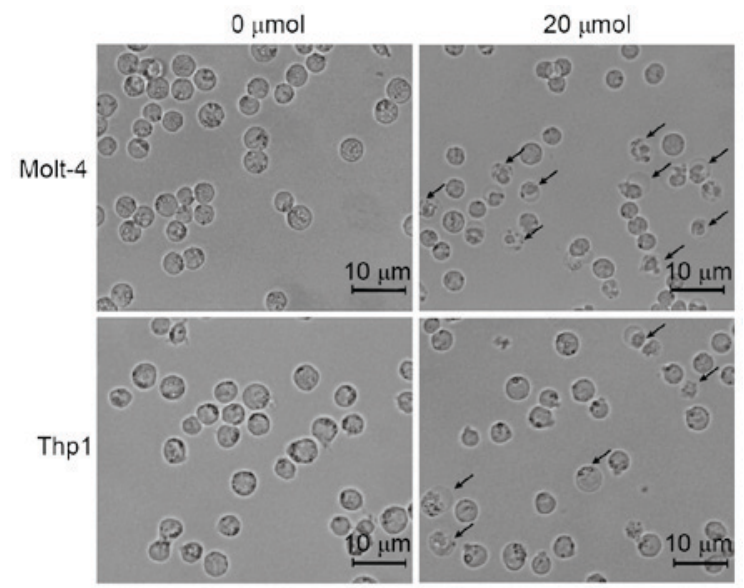

Figure 3. Morphological changes in Molt-4 and Thp1 cell lines treated with $20 \mu \mathrm{mol}$ loperamide for $24 \mathrm{~h}$. Cells treated with loperamide were observed by light microscopy directly (magnification, $\mathrm{x} 400$ ). Arrows indicate cells with typical morphological changes.

pathway in leukemia cells was activated and associated with the DNA damage following loperamide treatment. These findings uncover the anti-leukemia role and mechanism of loperamide. Thus, loperamide, used widely to treat leukemia, possesses therapeutic potential as an anti-leukemic agent.

The cancer cell lines used in preclinical studies have a vital role in the study of biological mechanisms of cancer and high throughput screening of effective antitumor drugs. However, gene aberrations in cancer cell lines occurring with increasing passage number has led to misrepresentative clinical scenarios, and thus limits their clinical correlation $(38,39)$. In a previous study, Gillet et al (38) investigated the multidrug resistance transcriptome of six cancer types in established cancer cell lines and clinical samples, and found no association between established cancer cell lines and clinical samples. Furthermore, considering that there are no two genetically identical samples even from the same patient, it is difficult for a small number of cancer cell lines to represent the genetic and epigenetic variation of millions of patients with cancer (40). Therefore, driven by personalized medicine, it is necessary to use primary tumor models to test the effectiveness of antitumor drugs to ensure the authenticity of patient-dependent tumor variability. In the present study, primary leukemia cells from 9 patients with AML and 6 patients with ALL were isolated. Notably, gene mutation and chromosome karyotype abnormalities existed in 10 patients, representing the patient-dependent tumor variability. Therefore, the result that the cytotoxic effect of loperamide was also observed in primary cells from patients with leukemia supported the anti-leukemia potential of loperamide.

Cell apoptosis, also termed programmed cell death, is a process occurring primarily through an evolutionarily conserved form of cell suicide and performs a significant role in animal development $(41,42)$. The dysregulation of this process is involved in the pathogenesis of a panel of human diseases, including cancer (41). Therefore, inducing tumor cell apoptosis is the pathway by which the majority of antitumor agents take effect (43). To investigate the cytotoxic mechanism of loperamide on leukemia cells, leukemia cells were treated with loperamide for $24 \mathrm{~h}$, and morphological changes were observed 
$\mathbf{A}$

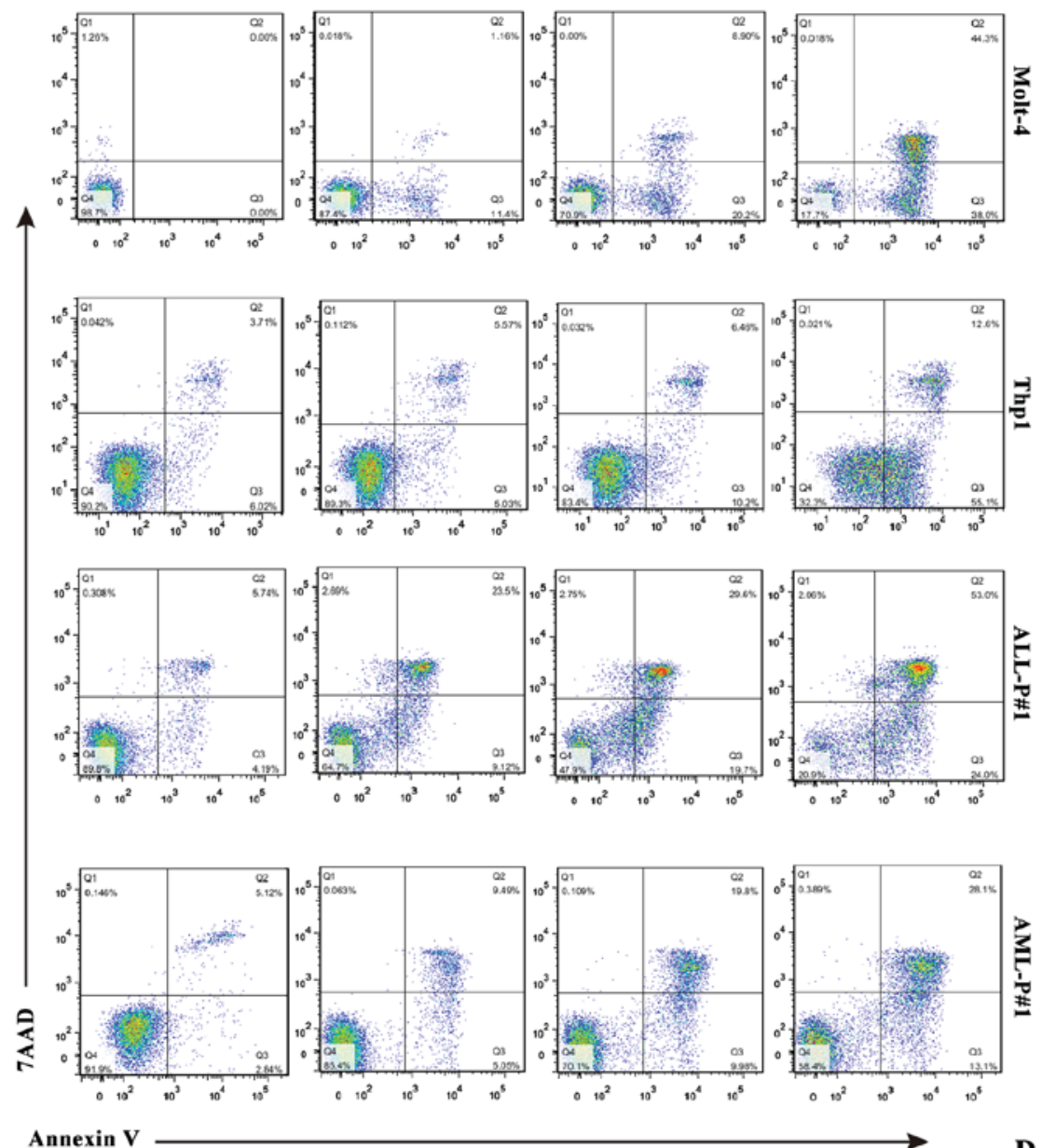

B
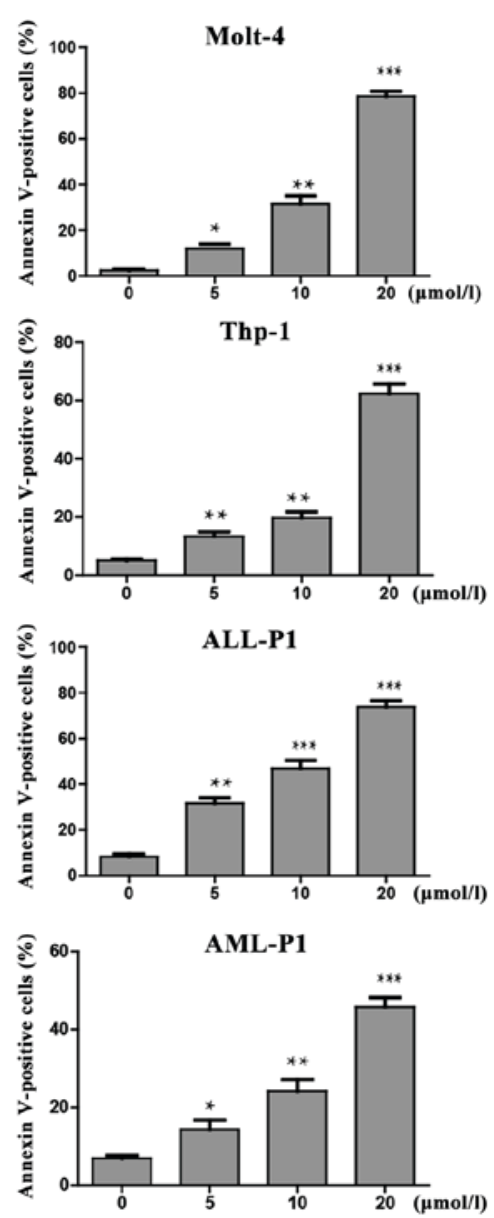

D

$\mathbf{C}$

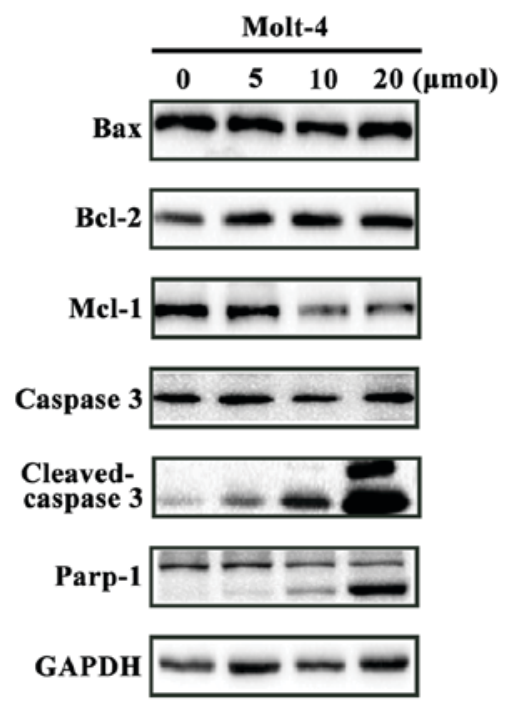

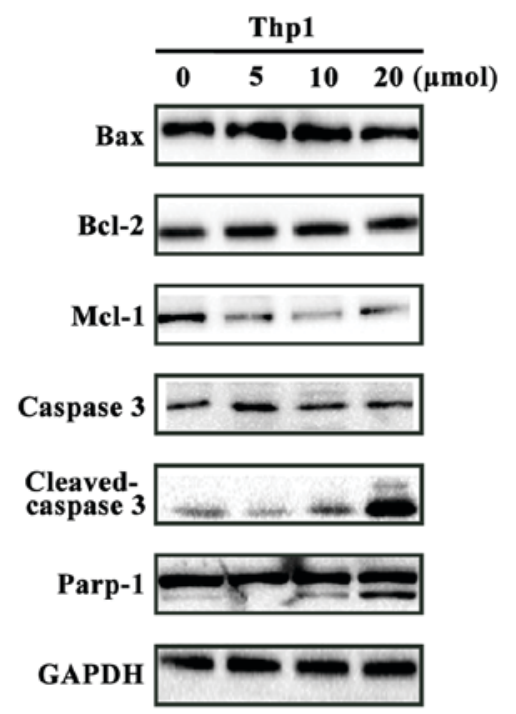
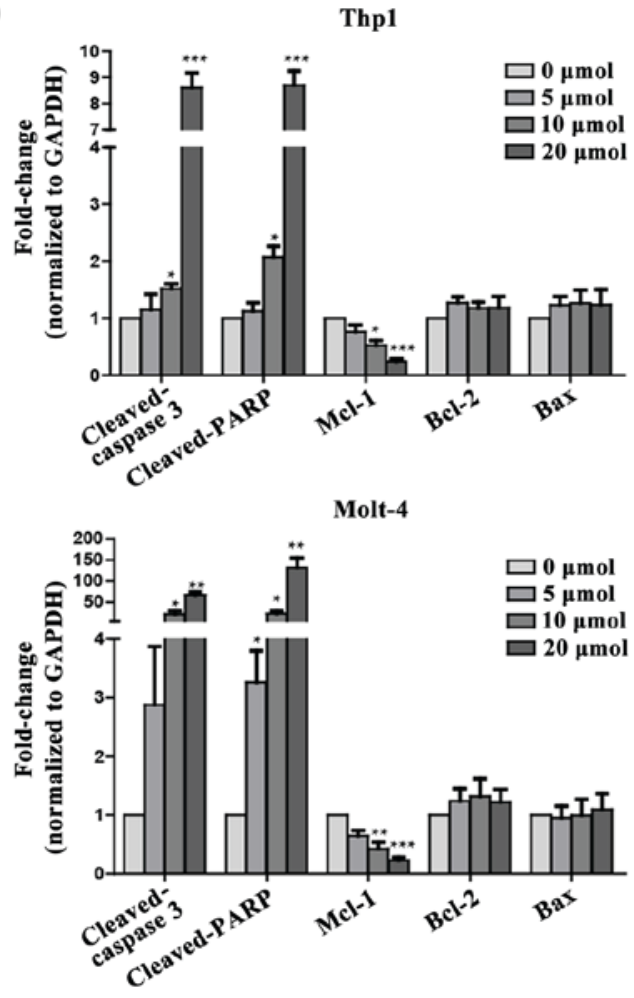

Figure 4. Loperamide induces apoptosis in leukemia cell lines and primary leukemia cells from patients in a concentration-dependent manner. (A) Molt-4, Thp1, ALL-P1 and AML-P1 cells were treated with various concentrations of loperamide for $24 \mathrm{~h}$ and apoptosis was determined by flow cytometry. (B) The percentage of cell apoptosis following treatment with loperamide. (C) Western blot analysis of caspase-3, cleaved-caspase-3, PARP, Bcl-2, Bax and Mcl-1 in Molt-4 and Thpl cells treated with loperamide for $24 \mathrm{~h}$. (D) Band quantification is shown as the fold change from control. The results are presented as the mean \pm standard deviation of three independent experiments. ${ }^{*} \mathrm{P}<0.05 ;{ }^{* *} \mathrm{P}<0.01 ;{ }^{* * *} \mathrm{P}<0.001$ vs. control group. PARP, poly(ADP-ribose) polymerase; Bcl-2, B-cell lymphoma-2; Bax, Bcl-2-associated X protein; Mcl-1, myeloid cell leukemia 1; acute lymphocytic leukemia-patient 1; AML-P1, acute myeloid leukemia-patient 1. 
A

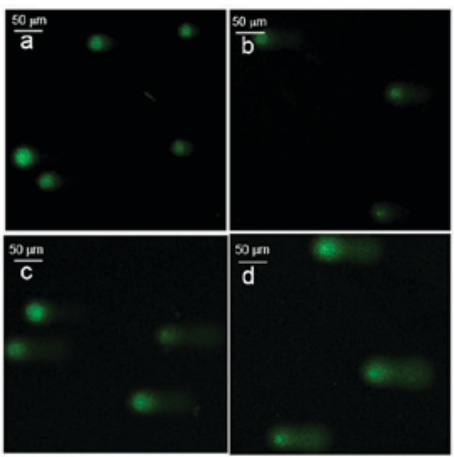

B
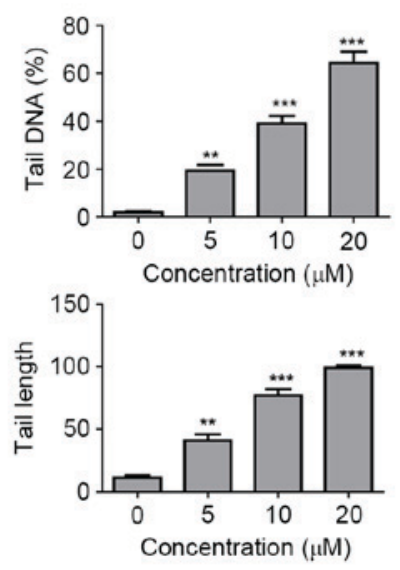

C
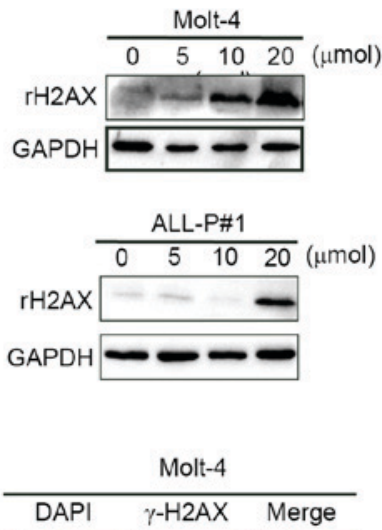
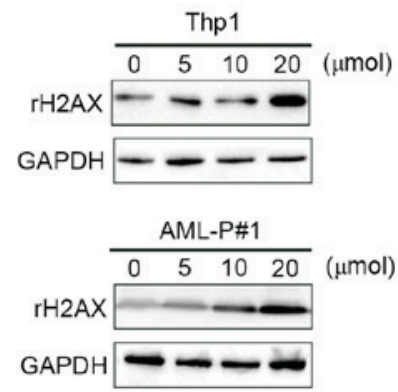

D

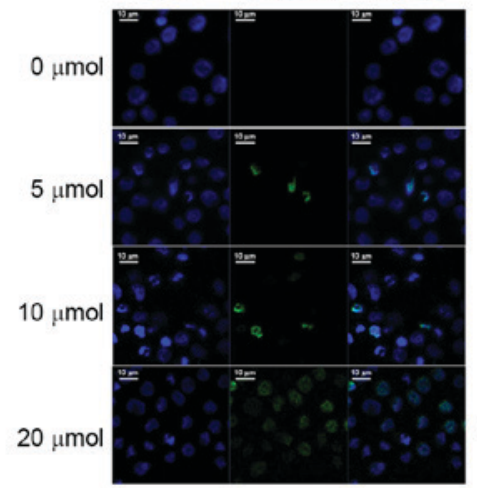

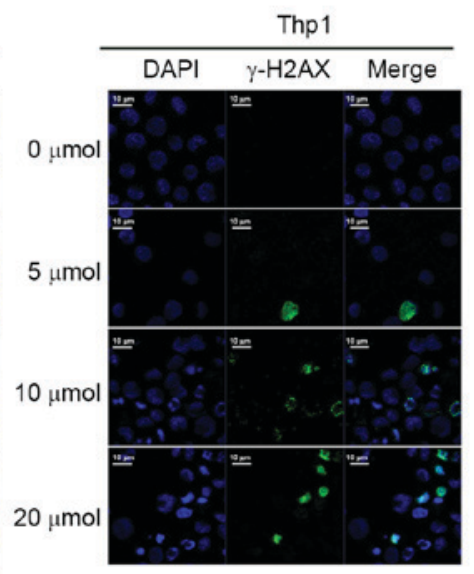

Figure 5. Loperamide induces DNA damage in leukemia cells. (A) The comet assay was used to determine the different levels of DNA damage (long tail) in Molt-4 cell lines following treatment with (a) solvent control, (b) $5 \mu \mathrm{mol}$, (c) $10 \mu \mathrm{mol}$ or (d) $20 \mu \mathrm{mol}$ loperamide for $24 \mathrm{~h}$. (B) DNA damage induced by loperamide in Molt-4 cell lines was characterized by the percentage of DNA tail and tail length. Molt-4, Thp1, ALL-P1 and AML-P1 cells were treated with various concentrations of loperamide for $24 \mathrm{~h}$ and the level of $\gamma$-H2AX was measured by (C) western blotting and (D) immunofluorescence staining. The results are presented as the mean \pm standard deviation of three independent experiments. ${ }^{* *} \mathrm{P}<0.01 ;{ }^{* * *} \mathrm{P}<0.001$ vs. control group. ALL-P1, acute lymphocytic leukemia-patient 1; AML-P1, acute myeloid leukemia-patient 1.
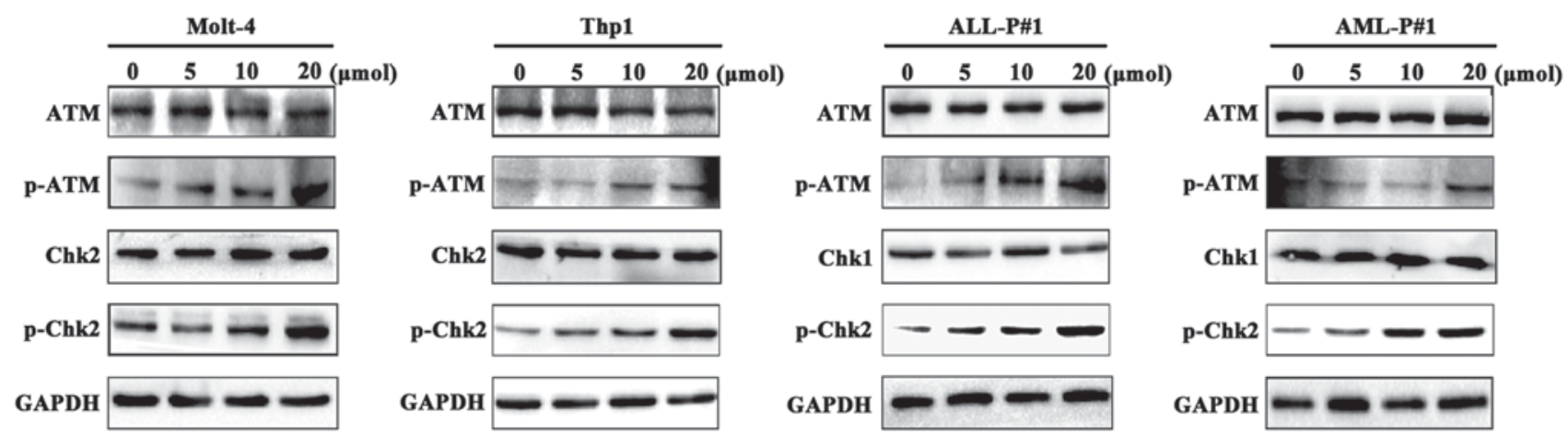

Figure 6. The ATM-Chk2 signaling pathway is activated in leukemia cells treated by loperamide. Immunoblotting of Molt-4, Thp1, ALL-P1 and AML-P1 cells treated with various concentrations of loperamide for $24 \mathrm{~h}$. ATM, ataxia telangiectasia mutated serine/threonine kinase; Chk2, checkpoint kinase 2; p, phosphorylated; acute lymphocytic leukemia-patient 1; AML-P1, acute myeloid leukemia-patient 1.

and flow cytometric cell apoptosis analyses were performed. The results supported the hypothesis that loperamide exerts a cytotoxic effect via inducing cell apoptosis. Caspase-3 activation followed by caspase-3-mediated cleavage of PARP has a critical role in apoptosis $(44,45)$. The results determined by western blotting of a dose-dependent generation of cleaved caspase- 3 and cleaved-PARP validated the assumption of the apoptosis-inducing effect of loperamide.

In addition to engaging in apoptosis, PARP is also involved in and has a vital effect in DNA damage repair by recognizing
DNA strand breaks and acting as a critical regulatory component (29). Furthermore, downregulation of Mcl-1 expression following loperamide treatment, together with evidence that Mcl-1 regulates the DNA damage response and overexpression promotes resistance to DNA damage, suggested the possible DNA damage-inducing effect of loperamide $(30,46)$. In the present study, the comet assay, which is a sensitive method of evaluating DNA damage in cells, showed a long tail length at the concentration of $20 \mu \mathrm{M}$ loperamide, evidence of DNA damage induced by loperamide treatment. The phosphorylation 
of histone $\mathrm{H} 2 \mathrm{~A}$ acts as a sensitive marker of DNA damage, which forms nuclear foci at sites of DNA damage and behaves as a signal to recruit other repair proteins (14). The results of western blotting and immunofluorescence staining indicated that the molecular sensor of DNA damage, $\mathrm{rH} 2 \mathrm{ax}$, increased in a dose-dependent manner following treatment with loperamide. To investigate the signaling pathway activated by DNA damage, the ATM-Chk2 pathway was investigated by western blotting. ATM is a kinase belonging to the PI3K signaling family and is commonly activated by double-strand DNA breaks (DSBs) (47). Once triggered by DSBs, ATM is activated and phosphorylates its downstream signaling proteins, including Chk2, which serves as a signal transducer and effector that is involved in the process of apoptosis initiation (32). Western blotting assays indicated that ATM was activated via its phosphorylation at Ser1981 subsequent to DNA damage being induced by loperamide treatment and subsequently initiating the downstream molecular Chk2. In addition, the alteration of numerous signaling pathways that perform crucial roles in tumor survival and apoptosis was also determined, including the NF- $\mathrm{B}$, JAK-STAT and PI3K/Akt pathways (25-27). The results revealed that these pathways were not activated (Fig. 3).

To conclude, the present study demonstrated for the first time that loperamide, an old drug used as an antidiarrheal agent, has therapeutic potential as an anti-acute leukemia agent. Loperamide effectively inhibits the growth of leukemia cell lines and primary leukemia cells through inducing cell apoptosis. In addition, a new antitumor mechanism of loperamide was identified in the present study: DNA damage. Furthermore, the ATM-Chk2 pathway activated by DNA damage in response to loperamide treatment is found in leukemia cell lines and primary leukemia cells. Therefore, the present study provides new insights into the therapeutic potential and antitumor mechanism of loperamide in leukemia.

\section{Acknowledgements}

The present study was supported by the Leukemia Research Innovative Team of Zhejiang Province (grant no. 2011R50015), Medical and Health Research Foundation of Zhejiang Province (grant no. 2017KY369).

\section{References}

1. Chen W, Zheng R, Baade PD, Zhang S, Zeng H, Bray F, Jemal A, Yu XQ and He J: Cancer statistics in China, 2015. CA Cancer J Clin 66: 115-132, 2016.

2. Siegel RL, Miller KD and Jemal A: Cancer statistics, 2015. CA Cancer J Clin 65: 5-29, 2015.

3. Eryilmaz E and Canpolat C: Novel agents for the treatment of childhood leukemia: An update. OncoTargets Ther 10: 3299-3306, 2017.

4. Showel MM and Levis M: Advances in treating acute myeloid leukemia. F1000prime Rep 6: 96, 2014.

5. Turpin F, Tubiana-Hulin M, Meeus L, Goupil A, Berlie J and Clavel B: Complications of antitumor and antileukemic chemotherapy. 1. Sem Hop 58: 2047-2057, 1982 (In French).

6. Hatzimichael E and Tuthill M: Hematopoietic stem cell transplantation. Stem Cells Cloning 3: 105-117, 2010.

7. Cox GJ, Matsui SM, Lo RS, Hinds M, Bowden RA, Hackman RC, Meyer WG, Mori M, Tarr PI, Oshiro LS, et al Etiology and outcome of diarrhea after marrow transplantation: A prospective study. Gastroenterology 107: 1398-1407, 1994.
8. Geller RB, Gilmore CE, Dix SP, Lin LS, Topping DL, Davidson TG, Holland HK and Wingard JR: Randomized trial of loperamide versus dose escalation of octreotide acetate for chemotherapy-induced diarrhea in bone marrow transplant and leukemia patients. Am J Hematol 50: 167-172, 1995.

9. Gong XW, Xu YH, Chen XL and Wang YX: Loperamide, an antidiarrhea drug, has antitumor activity by inducing cell apoptosis. Pharmacol Res 65: 372-378, 2012.

10. Regan RC, Gogal RM Jr, Barber JP, Tuckfield RC, Howerth EW and Lawrence JA: Cytotoxic effects of loperamide hydrochloride on canine cancer cells. J Vet Med Sci 76: 1563-1568, 2014.

11. Goldar S, Khaniani MS, Derakhshan SM and Baradaran B: Molecular mechanisms of apoptosis and roles in cancer development and treatment. Asian Pac J Cancer Prev 16: 2129-2144, 2015.

12. Smart DJ, Halicka HD, Schmuck G, Traganos F, Darzynkiewicz Z and Williams GM: Assessment of DNA double-strand breaks and gammaH2 $\mathrm{AX}$ induced by the topoisomerase II poisons etoposide and mitoxantrone. Mutat Res 641: 43-47, 2008.

13. Leoni LM, Bailey B, Reifert J, Bendall HH, Zeller RW, Corbeil J, Elliott G and Niemeyer CC: Bendamustine (Treanda) displays a distinct pattern of cytotoxicity and unique mechanistic features compared with other alkylating agents. Clin Cancer Res 14: 309-317, 2008

14. van Attikum H and Gasser SM: The histone code at DNA breaks: A guide to repair? Nat Rev Mol Cell Biol 6: 757-765, 2005.

15. Zhou BB, Chaturvedi P, Spring K, Scott SP, Johanson RA, Mishra R, Mattern MR, Winkler JD and Khanna KK: Caffeine abolishes the mammalian G(2)/M DNA damage checkpoint by inhibiting ataxia-telangiectasia-mutated kinase activity. J Biol Chem 275: 10342-10348, 2000.

16. Gatei M, Sloper K, Sorensen C, Syljuäsen R, Falck J, Hobson K, Savage K, Lukas J, Zhou BB, Bartek J and Khanna KK: Ataxia-telangiectasia-mutated (ATM) and NBS1-dependent phosphorylation of Chk1 on Ser-317 in response to ionizing radiation. J Biol Chem 278: 14806-14811, 2003.

17. Lavin MF, Birrell G, Chen P, Kozlov S, Scott S and Gueven N: ATM signaling and genomic stability in response to DNA damage. Mutat Res 569: 123-132, 2005.

18. Niida $\mathrm{H}$ and Nakanishi M: DNA damage checkpoints in mammals. Mutagenesis 21: 3-9, 2006.

19. Jackson SP and Bartek J: The DNA-damage response in human biology and disease. Nature 461: 1071-1078, 2009.

20. Nijhawan D, Fang M, Traer E, Zhong Q, Gao W, Du F and Wang X: Elimination of Mcl-1 is required for the initiation of apoptosis following ultraviolet irradiation. Genes Dev 17: 1475-1486, 2003.

21. Sabattini E, Bacci F, Sagramoso C and Pileri SA: WHO classification of tumours of haematopoietic and lymphoid tissues in 2008: An overview. Pathologica 102: 83-87, 2010.

22. Końca K, Lankoff A, Banasik A, Lisowska H, Kuszewski T, Góźdź S, Koza Z and Wojcik A: A cross-platform public domain PC image-analysis program for the comet assay. Mutat Res 534: 15-20, 2003.

23. Czabotar PE, Lessene G, Strasser A and Adams JM: Control of apoptosis by the BCL-2 protein family: Implications for physiology and therapy. Nat Rev Mol Cell Biol 15: 49-63, 2014.

24. Lazebnik YA, Kaufmann SH, Desnoyers S, Poirier GG and Earnshaw WC: Cleavage of poly(ADP-ribose) polymerase by a proteinase with properties like ICE. Nature 371: 346-347, 1994.

25. Perkins ND: Integrating cell-signalling pathways with NF-kappaB and IKK function. Nat Rev Mol Cell Biol 8: 49-62, 2007.

26. Catlett-Falcone R, Landowski TH, Oshiro MM, Turkson J, Levitzki A, Savino R, Ciliberto G, Moscinski L, Fernández-Luna JL, Nuñez G, et al: Constitutive activation of Stat3 signaling confers resistance to apoptosis in human U266 myeloma cells. Immunity 10: 105-115, 1999.

27. Martelli AM, Nyåkern M, Tabellini G, Bortul R, Tazzari PL, Evangelisti C and Cocco L: Phosphoinositide 3-kinase/Akt signaling pathway and its therapeutical implications for human acute myeloid leukemia. Leukemia 20: 911-928, 2006.

28. Yao H, Mi S, Gong W, Lin J, Xu N, Perrett S, Xia B, Wang J and Feng Y: Anti-apoptosis proteins Mcl-1 and Bcl-xL have different p53-binding profiles. Biochemistry 52: 6324-6334, 2013.

29. Molinete M, Vermeulen W, Bürkle A, Ménissier-de Murcia J, Küpper JH, Hoeijmakers JH and de Murcia G: Overproduction of the poly(ADP-ribose) polymerase DNA-binding domain blocks alkylation-induced DNA repair synthesis in mammalian cells. EMBO J 12: 2109-2117, 1993. 
30. Jamil S, Stoica C, Hackett TL and Duronio V: MCL-1 localizes to sites of DNA damage and regulates DNA damage response. Cell Cycle 9: 2843-2855, 2010

31. Swain U and Subba Rao K: Study of DNA damage via the comet assay and base excision repair activities in rat brain neurons and astrocytes during aging. Mech Ageing Dev 132: 374-381, 2011.

32. Zhou BB and Elledge SJ: The DNA damage response: Putting checkpoints in perspective. Nature 408: 433-439, 2000.

33. StokbroekxRA,VandenberkJ,VanHeertumAH,VanLaarGM,Van der Aa MJ, Van Bever WF and Janssen PA: Synthetic antidiarrheal agents. 2,2-Diphenyl-4-(4'-aryl-4'-hydroxypiperidino) butyramides. J Med Chem 16: 782-786, 1973.

34. Awouters F, Niemegeers CJ and Janssen PA: Pharmacology of antidiarrheal drugs. Annu Rev Pharmacol Toxicol 23: 279-301, 1983.

35. Clay GA, Mackerer CR and Lin TK: Interaction of loperamide with $[3 \mathrm{H}]$ naloxone binding sites in guinea pig brain and myenteric plexus. Mol Pharmacol 13: 533-540, 1977.

36. Harper JL, Shin Y and Daly JW: Loperamide: A positive modulator for store-operated calcium channels? Proc Natl Acad Sci USA 94: 14912-14917, 1997.

37. Merritt JE, Brown BL and Tomlinson S: Loperamide and calmodulin. Lancet 1: 283, 1982.

38. Gillet JP, Calcagno AM, Varma S, Marino M, Green LJ, Vora MI, Patel C, Orina JN, Eliseeva TA, Singal V, et al: Redefining the relevance of established cancer cell lines to the study of mechanisms of clinical anti-cancer drug resistance. Proc Natl Acad Sci USA 108: 18708-18713, 2011.

39. Gazdar AF, Gao B and Minna JD: Lung cancer cell lines: Useless artifacts or invaluable tools for medical science? Lung cancer 68 : $309-318,2010$
40. Kirk R: Genetics: Personalized medicine and tumour heterogeneity. Nat Rev Clin Oncol 9: 250, 2012.

41. Thompson CB: Apoptosis in the pathogenesis and treatment of disease. Science 267: 1456-1462, 1995

42. Jacobson MD, Weil M and Raff MC: Programmed cell death in animal development. Cell 88: 347-354, 1997.

43. Westhoff MA, Marschall N and Debatin KM: Novel approaches to apoptosis-inducing therapies. Adv Exp Med Biol 930: 173-204, 2016.

44. Salvesen GS and Dixit VM: Caspases: Intracellular signaling by proteolysis. Cell 91: 443-446, 1997.

45. Simbulan-Rosenthal CM, Rosenthal DS, Iyer S, Boulares AH and Smulson ME: Transient poly(ADP-ribosyl)ation of nuclear proteins and role of poly(ADP-ribose) polymerase in the early stages of apoptosis. J Biol Chem 273: 13703-13712, 1998.

46. Mills JR, Malina A and Pelletier J: Inhibiting mitochondrial-dependent proteolysis of Mcl-1 promotes resistance to DNA damage. Cell Cycle 11: 88-98, 2012.

47. Lee JH and Paull TT: Activation and regulation of ATM kinase activity in response to DNA double-strand breaks. Oncogene 26: 7741-7748, 2007

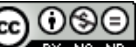

This work is licensed under a Creative Commons Attribution-NonCommercial-NoDerivatives 4.0 International (CC BY-NC-ND 4.0) License. 